\title{
A numerical Study of Single Column Adsorber for Optimal Design of Pressure Swing Adsorption
}

\author{
Abdulbasit H. Mahdi, Safaa M.R. Ahmed, Heba S. Ayuob \\ Department of Chemical Engineering, College of Engineering, Tikrit Unversity „, Iraq, Tikrit
}

\begin{abstract}
Four different configurations of pressure swing adsorption (PSA) were designed numerically using Matlab software. The PSA system was applied to separate oxygen from air. The software was used first to validate previous experimental results of single bed adsorber. The results showed that the breakthrough time with product pressurizing is about $1000 \mathrm{~s}$ and mass transfer zone (MTZ) is steeper, while with the air pressurizing happened within 60 s and MTZ was very wide. High purity of oxygen $(>90 \%)$ was observed with the first and fourth configuration. Purity of about $88 \%$ was achieved with the third configuration, and low purity (75\%) with the second configuration. In addition, high power consumption was indicated by the first, and second configurations. However, the third and fourth configurations consumed low power due to the pressure equalization step. Based on the results, the more economic and effective design is the fourth configuration.
\end{abstract}

\section{Introduction}

Pressure swing adsorption (PSA) unit becomes an alternative and more efficient process for oxygen separation from air than the cryogenic process, because of the low power consumption, availability, flexibility, fully automated operation of the process. [1] In 1932 the first unit of a single bed of the PSA process was developed by Finlayson and Sharp. In 1960, the first unit of dual bed PSA process was designed by Skarstrom for drying process. [2-8]

In the last decades a lot of studies have carefully investigated the performance of the PSA unit experimentally and theoretically to improve process performance. The following modifications were taken into account, such as: pressure equalization step, vacuum pressurizing step, product pressurizing step, increase number of step per one cycle, increase number of columns, and modify adsorbent characterization. All studies considered the effects of various process parameters. For instance : adsorption pressure, cycle time, purge flowrate, product flowrate, break through time on the PSA process performance. Which was indicated by the product purity, recovery, and energy consumption. [9-24]

Commercial zeolites $13 \mathrm{X}$ and $5 \mathrm{~A}$ almost were used as adsorbents for air separation by PSA process. The maximum purity is limited to $95 \%$ oxygen because of the argon presence in the air and because the similar adsorption capacities of oxygen and argon on the zeolite adsorbents.[25-27 ]

Although of neuroses studies introduced about PSA process, but no one focused on the comparison between different design of the PSA process to summarize the performance of each other. As a result of computer power development in the last decade, several computer programs for chemical engineering process are available for mode ling and simulation for deeply investigation of the dynamic behavior of the pressure swing adsorption. [13, 15-18 ]

The aim of th is study was to verify a mathe matical model using experimental data for single bed adsorber from literature [25]. Then, the validated model will be used to design four configurations of PSA processes for comparis on such as: 2-bed 4-step with air feed pressurizing, 2-bed 4-step with product pressurizing, 2bed 6-step with pressure equalization processes, and 2-bed 6-step with pressure equalization processes as well as product pressurizing. Moreover, evaluation the effect of operation parameters such as purge flowrate, cycle time, and product flowrate on the process performance, and power consumption of each process. 


\section{Mathematical Model}

Modeling and simulation are carried out to study and analyze the effect of air and product pressurizing on the process performance of a single column adsorber for oxygen separation from air, as a basic preliminary step to improve the design of a PSA process, through the following configurations:

1- Two-bed 4-step with air pressurizing.

2- Two-bed 4-step with product pressurizing.

3- Two-bed 6-step with equalization step.

4- Two-bed 6-step with equalization step plus product press urizing.

PSA process described in details in litreatures. [25,26] Modeling of the PSA process involves a set of partial differential equations (PDEs), ordinary differential equations (ODE), and algebra equations with periodic boundary conditions. The solution of these sets of equations by an analytical technique is difficult, therefore, a simulation program (MATLAB) is used to solve set of equations. The centered finite difference method employed to discretize the axial dimension into 160 discretization. The product oxygen purity, recovery, and power consumption are used as an indication of the process performance. The following assumptions were considered in the mathematical model:

1- Feed composition assumed to be $\left(\mathrm{O}_{2}: 21 \%, \mathrm{~N}_{2}: 78 \%\right.$, Ar: $\left.1 \%\right)$.

2- Ideal gas law is employed, as suggested in [ 7,12, 18,26]

3- The systemis is othermal.[7,8,20]

4- Axial dispersion plug flow model is used to describe the flow pattern.

5- Radial concentration is negligible.

6- Mass Transfer transport is described by linear driving force (LDF).

7- Equilibrium relationship for oxygen, nitrogen, and argon is represented by Lang muir-Freundlich equation.

8- Pressure drop is represented by Ergun equation.

Over all material balance

$$
\frac{\partial \mathrm{C}}{\partial \mathrm{t}}+\frac{\partial(\mathrm{uC})}{\partial \mathrm{t}}+\sum_{\mathrm{i}=1}^{\mathrm{n}} \rho \mathrm{p}\left(\frac{1-\varepsilon}{\varepsilon}\right) \frac{\overline{\partial \mathrm{q}}}{\partial \mathrm{t}}=0
$$

Component (i) material balance :

$$
-\mathrm{D}_{\mathrm{L}} \frac{\partial^{2} c_{i}}{\partial \mathrm{z}^{2}}+\frac{\partial\left(\mathrm{u} c_{i}\right)}{\partial \mathrm{z}}+\frac{\partial c_{i}}{\partial \mathrm{t}}+\rho_{\mathrm{P}}\left(\frac{1-\varepsilon}{\varepsilon}\right) \frac{\partial \mathrm{q}_{\mathrm{i}}}{\partial \mathrm{t}}=0
$$

Boundary conditions of mass balances are presented in table 1. The well-known Danckwerts boundary conditions are applied [28]. The adsorption parameters for both of the Langmuir-Freundlich and LDF equations are presented in table 2. The design and operating variables of the single column process are shown in table 3. The operation parameters of four configurations of PSA processes are shown in table4.

Table 1: Boundary conditions used in the mathematical model and simulation process.

\begin{tabular}{lll}
\hline Step & Concentration $(\mathrm{Ci})$ & Velocity $(\mathrm{u})$ \\
\hline \multirow{2}{*}{ Pressurizing (Pre) } & $-\left.\mathrm{DL}\left(\partial \mathrm{c}_{\mathrm{i}} / \partial \mathrm{z}\right)\right|_{\mathrm{z}=0}=\mathrm{u}\left(\left.\mathrm{c}_{\mathrm{i}}\right|_{\mathrm{z}=0-}-\left.\mathrm{c}_{\mathrm{i}}\right|_{\mathrm{z}=0+}\right)$ & $\begin{array}{l}\mathrm{u}_{\mathrm{z}=0}=\mathrm{u}_{\text {feed }} \\
\left.\mathrm{u}\right|_{\mathrm{z}=\mathrm{L}}=0\end{array}$ \\
& $\left.\left(\partial \mathrm{c}_{\mathrm{i}} / \partial \mathrm{z}\right)\right|_{\mathrm{z}=\mathrm{L}=0}$ & \\
& $-\left.\mathrm{DL}\left(\partial \mathrm{c}_{\mathrm{i}} / \partial \mathrm{z}\right)\right|_{\mathrm{z}=0}=\mathrm{u}\left(\left.\mathrm{c}_{\mathrm{i}}\right|_{\mathrm{z}=0-}-\left.\mathrm{c}_{\mathrm{i}}\right|_{\mathrm{z}=0+}\right)$ & $\left.\mathrm{u}\right|_{\mathrm{z}=0}=\mathrm{u}_{\text {feed }}$ \\
Adsorption (Ads) & $\left.\left(\partial \mathrm{c}_{\mathrm{i}} / \partial \mathrm{z}\right)\right|_{\mathrm{z}=\mathrm{L}=0}$ & \\
& & \\
Depressure & $-\left.\mathrm{DL}\left(\partial \mathrm{c}_{\mathrm{i}} / \partial \mathrm{z}\right)\right|_{\mathrm{z}=0=0}$ & \\
Equalization (DepEqu) & $-\left.\mathrm{DL}\left(\partial \mathrm{c}_{\mathrm{i}} / \partial \mathrm{z}\right)\right|_{\mathrm{z}=\mathrm{L}=0}$ & \\
& $\left.\mathrm{D}_{\mathrm{L}}\left(\partial \mathrm{c}_{\mathrm{i}} / \partial \mathrm{z}\right)\right|_{\mathrm{z}=0}=0$ & $\left.\mathrm{u}\right|_{\mathrm{z}=\mathrm{L}=0}$ \\
Depressurizing (Dep) & $-\left.\mathrm{D}_{\mathrm{L}}\left(\partial \mathrm{c}_{\mathrm{i}} / \partial \mathrm{z}\right)\right|_{\mathrm{z}=\mathrm{L}=0}$ &
\end{tabular}




$\begin{array}{lll} & -\left.\mathrm{D}_{\mathrm{L}}\left(\partial \mathrm{c}_{\mathrm{i}} / \partial \mathrm{z}\right)\right|_{\mathrm{z}=\mathrm{L}=\mathrm{u}\left(\left.\mathrm{c}_{\mathrm{i}}\right|_{\mathrm{z}=\mathrm{L}+}-\left.\mathrm{c}_{\mathrm{i}}\right|_{\mathrm{z}=\mathrm{L}-}\right)} & \left.\mathrm{u}\right|_{\mathrm{z}=\mathrm{L}}=\mathrm{u}_{\text {purge }} \\ & -\left.\mathrm{D}_{\mathrm{L}}\left(\partial \mathrm{c}_{\mathrm{i}} / \partial \mathrm{z}\right)\right|_{\mathrm{z}=0}=0 & \\ \text { Purging (Pur) } & & \left.\mathrm{u}\right|_{\mathrm{z}=0}=0 \\ \begin{array}{l}\text { Pressure Equalization } \\ \text { (PreEqu) }\end{array} & -\left.\mathrm{D}_{\mathrm{L}}\left(\partial \mathrm{c}_{\mathrm{i}} / \partial \mathrm{z}\right)\right|_{\mathrm{z}=0}=\mathrm{u}\left(\left.\mathrm{c}_{\mathrm{i}}\right|_{\mathrm{z}=0-}-\left.\mathrm{c}_{\mathrm{i}}\right|_{\mathrm{z}=0+}\right) & \\ & \left.\left(\partial \mathrm{c}_{\mathrm{i}} / \partial \mathrm{z}\right)\right|_{\mathrm{z}=\mathrm{L}=0}=0\end{array}$

Initial conditions are shown below:

$\mathrm{c}_{\mathrm{i}}(\mathrm{z}, 0)=\mathrm{c}_{0} ; \quad \mathrm{q}_{\mathrm{i}}(\mathrm{z}, 0)=\mathrm{q}_{\mathrm{i}}^{*}$

Ideal gas law

$\frac{\mathrm{P}}{\mathrm{RT}}=\sum_{\mathrm{i}=1}^{\mathrm{n}} \mathrm{c}_{\mathrm{i}}$

The sorption rate is described by the LDF equation with a single lumped mass -transfer parameter:

$$
\frac{\partial \overline{\mathrm{q}}_{\mathrm{i}}}{\partial \mathrm{t}}=\omega\left(\mathrm{q}_{\mathrm{i}}^{*}-\overline{\mathrm{q}}_{\mathrm{i}}\right)
$$

The axial dispersion coefficient $\mathrm{D}_{\mathrm{L}}$ estimated by the fitting between the mathematical model and experimental data from literature survey for single colu mn adsorber by minimizing the sum square error in equation 5. The predict values were $0.27888 \mathrm{~m}^{2} / \mathrm{sec}$ for an air feed pressurizing and $0.00244 \mathrm{~m}^{2} / \mathrm{sec}$ for product feed pressurizing.

Sum of square error:

$S S E=\sum_{i=1}^{n}\left(y_{i}^{\text {exp }}-y_{i}^{c a l}\right)^{2}$

The adsorption equilibrium of oxygen, nitrogen, and argon were predicted by the Lang muir-Freundlich equation:

$$
q_{i}=\frac{q_{m i} B_{i} P_{i}^{n i}}{1+\sum_{j=1}^{n} B_{j} P_{j}^{n j}}
$$

Where: $\mathrm{q}_{\mathrm{m}}=\mathrm{k}_{1}+\mathrm{k}_{2} \mathrm{~T}, \mathrm{~B}=\mathrm{k}_{3} \exp \left(\frac{\mathrm{k}_{4}}{\mathrm{~T}}\right)$, and $\mathrm{n}_{\mathrm{i}}=\mathrm{k}_{5}+\frac{\mathrm{k}_{6}}{\mathrm{~T}}$

Table 2. Values of adsorption isotherm Parameters, and LDF Coefficient wi for Zeolite 13X [12].

\begin{tabular}{llll}
\hline Parameters & $\mathrm{N}_{2}$ & $\mathrm{O}_{2}$ & $\mathrm{Ar}$ \\
\hline $\mathrm{K}_{1} * 10^{3}(\mathrm{~mol} / \mathrm{g})$ & 12.52 & 6.705 & 6.705 \\
$\mathrm{~K}_{2} * 10^{5}(\mathrm{~mol} / \mathrm{g})$ & -1.785 & -1.435 & -1.435 \\
$\mathrm{~K}_{3} * 10^{5}(1 / \mathrm{atm})$ & 2.154 & 3.253 & 3.253 \\
$\mathrm{~K}_{4}(\mathrm{k})$ & 2333 & 1428 & 1428 \\
$\mathrm{~K}_{5}$ & 1.666 & -0.3169 & -0.3169 \\
$\mathrm{~K}_{6}(\mathrm{k})$ & -245.2 & 387.8 & 387.8 \\
$\omega \mathrm{i}\left(\mathrm{s}^{-1}\right)$ & 0.197 & 0.62 & 0.62 \\
\hline
\end{tabular}

Pressure drop effect along the bed is described by Ergun equation

$$
-\frac{\mathrm{dP}}{\mathrm{dz}}=\frac{150 \mu(1-\epsilon)^{2}}{4 \mathrm{R}_{\mathrm{p}}^{2} \epsilon^{3}} \mathrm{u}+1.75 \frac{(1-\epsilon)}{2 \mathrm{R}_{\mathrm{p}}^{2} \epsilon^{3}}
$$

where $\mathrm{u}$ is superficial velocity.

Table 3: Parameters and operation conditions for single bed adsorber.

\begin{tabular}{ll}
\hline Parameters & Value \\
\hline Feed Composition & $\mathrm{O}_{2}: 21 \%, \mathrm{~N}_{2}: 78 \%$, Ar:1\% \\
Adsorbent & $13 \mathrm{X}$ \\
Bed length $(\mathrm{m})$ & 4 \\
Bed diameter $(\mathrm{m})$ & 0.0254 \\
Particle diameter (mm) & $1.7 * 10^{-3}$ \\
Bed voidage $(\varepsilon)$ & 0.35 \\
Ambient temperature $\left({ }^{\circ} \mathrm{C}\right)$ & 25 \\
Adsorption pressure (bar) & 5 \\
Range of initial pure oxygen & $1-5$ \\
pressurizing (bar) & \\
Product flowrate (liter/min) & 1 \\
\hline
\end{tabular}


The work consumption and power of all configurations are estimated by the pressure ratio $\left(\mathrm{P}_{\mathrm{H}} / \mathrm{P}_{\mathrm{L}}\right)$, $\left(\mathrm{P}_{\mathrm{H}} / \mathrm{P}_{\mathrm{Eq}}\right)$, and quantities of air flowing through the compressor in the pressurizing and producing steps. The compressor is assumed to be adiabatic (100\% efficiency) and is given by the following equations.

$\mathrm{W}=\left(\frac{\mathrm{k}}{\mathrm{k}-1}\right) \operatorname{nRT}\left(\left(\frac{\mathrm{P}}{\mathrm{P}_{\mathrm{atm}}}\right)^{\frac{\mathrm{k}-1}{\mathrm{k}}}-1\right)$

Power $=\frac{\int_{0}^{\mathrm{t}_{\mathrm{P}}+\mathrm{t}_{\mathrm{A}}}(\text { work }) \cdot \mathrm{dt} \mid \text { bed }_{1}+\int_{0}^{\mathrm{t}_{\mathrm{p}}+\mathrm{t}_{\mathrm{A}}} \text { (work).dt } \mid \text { bed }_{2}}{\text { cycle time }}$

where $\mathrm{k}$ is the ratio of the specific heat capacity at constant pressure to the specific heat capacity at constant volume (for air, $\mathrm{k}=1.4$ ) $[6,29]$.

The performance of a PSA process is indicated on the basis of product oxygen purity and product oxygen recovery as shown below:

$$
\begin{aligned}
& \text { amount of oxygen obtained during } \\
& \text { Purity }\left(\mathrm{O}_{2} \%\right)=\frac{\text { adsorption step in the product stream }}{\text { amount of total product obtained during }} \\
& \text { adsorption step in the product stream } \\
& \text { amount of oxygen obtained during } \\
& \text { Recovery }\left(\mathrm{O}_{2} \%\right)=\frac{\text { adsorption step in the product stream }}{\text { amount of oxygen fed during pressurizing, }}
\end{aligned}
$$

Table 4: Operation conditions investigated in the simulation process of four configurations of PSA processes [3,11,12,17,25,26]

\begin{tabular}{llll}
\hline & Pressure & Product flowrate \\
Mode & (bar) & (liter/min) & $\begin{array}{l}\text { Purge flowrate } \\
\text { (liter/min) }\end{array}$
\end{tabular}

\section{Cycle time (sec)}

Pre- Ads-Dep-Pur 2-bed 4-step

with product pressurizing (mode 1)

2-bed 4-step with air pressurizing 5 (mode 2)
$10-50-10-50$
$10-100-10-100$
$10-150-10-150$
$10-200-10-200$
$10-250-10-250$
$10-300-10-300$

Pre- Ads-Dep -Pur

10-30-10-30

$10-40-10-40$

$10-50-10-50$

10-60-10-60

10-100-10-100

10-150-10-150

Pre- Ads-DepEq -Dep -Pur - PreEq

2-bed 6-step with equalization (mode 3)

$5 \quad 1-10$ 1-15 
2-bed 6-step with equalization and product pressurizing

(mode 4)

\begin{tabular}{l} 
Pre- Ads-DepEq -Dep -Pur - PreEq \\
\hline $10-30-5-10-30-5$ \\
$10-40-5-10-40-5$ \\
$10-50-5-10-50-5$ \\
$10-60-5-10-60-5$ \\
$10-100-5-10-100-5$ \\
$10-150-5-10-100-5$
\end{tabular}

\section{Results and Discussion}

\subsection{Single column adsorber}

Figure 1 represents the breakthrough curve of oxygen separation from air by single column adsorber at 5 bar with air pressurizing. The effluent flow rate was 1 liter/min. The mixture of $\left(\mathrm{O}_{2}: 21 \%, \mathrm{~N}_{2}: 78 \%, \operatorname{Ar}: 1 \%\right)$ used as a feed, and the oxygen purity in the product stream used as an indication of breakthrough curve. The purity was about $88 \%$ till $60 \mathrm{~s}$, then dramatically decreased to $45 \%$ at around 200 s, and then gradually decreased to be stable at purity of about $20 \%$. The breakthrough time occurred at 60 s, which was too early, by comparing with total time of breakthrough curve of about 650s. In practical work the producing step should be stopped at an early time to avoid contamination of product. The length of MTZ is very wide, which means that the rate of mass transfer is very low and axial dispersion is very high due to the large particle size of adsorbent (1.7-2.6 mm). Air pressurizing increased the axial dispersion of nitrogen. The axial dispersion $D_{L}$ value used as an adjustable value to prove a fitting between the experimental results and the mathematical model. It was about $0.27888 \mathrm{~m}^{2} / \mathrm{s}$. It is very high and is interpreted the early breakthrough time of the process.

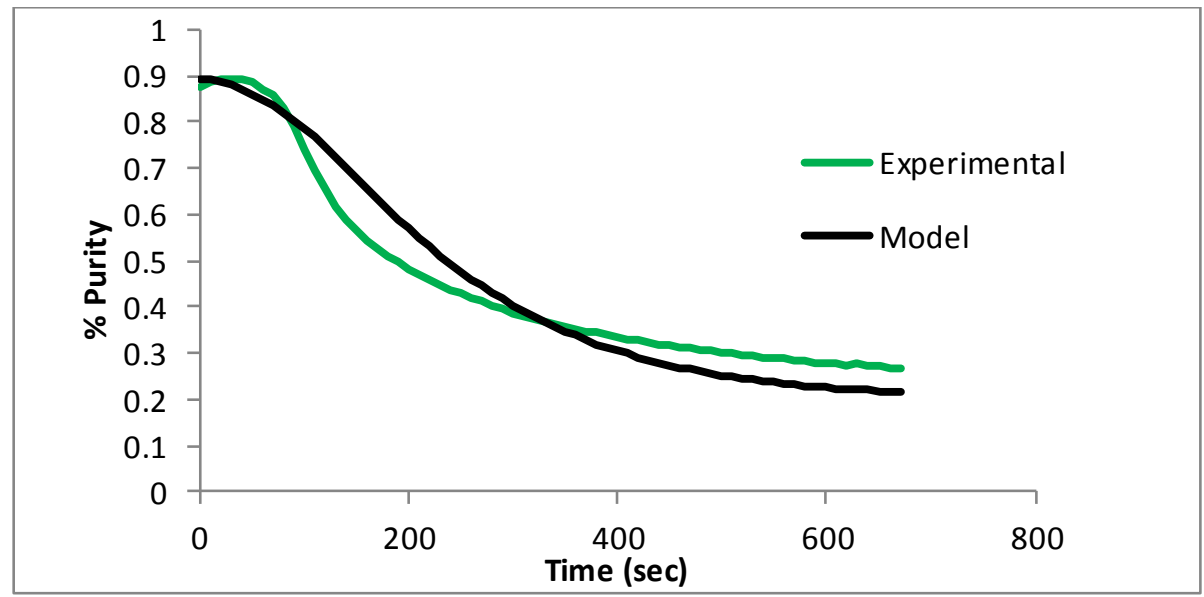

Fig. 1: Validation of break through curve of single column adsorber with air pressurization of oxygen separation from air at 5 bar using data from literature [25]

Figure 2 represents the effect of intermediate product pressurizing on the separation performance. The results showed that the performance is better, where the product purity was about $95 \%$ for a thousand seconds at an effluent rate of $1 \mathrm{liter} / \mathrm{min}$. As well as the mass transfer zone being steeper than the air pressurization. The obtained axial dispersion coefficient $D_{L}$ was about $0.00244 \mathrm{~m}^{2} / \mathrm{sec}$ from the fitting between the experimental results and the model. It was very low in comparison with $\mathrm{D}_{\mathrm{L}}$ of air pressurizing mentioned before, causing the breakthrough curve to occur too late. To sum up, the modeling is in good agreement with experimental results and the performance of the air separation with intermediate product 
pressurizing is better than the air pressurizing at the same conditions. The same trend of MTZ shape is observed with Kim et al.[13], Li et al.[23] , and Serbezov [24].

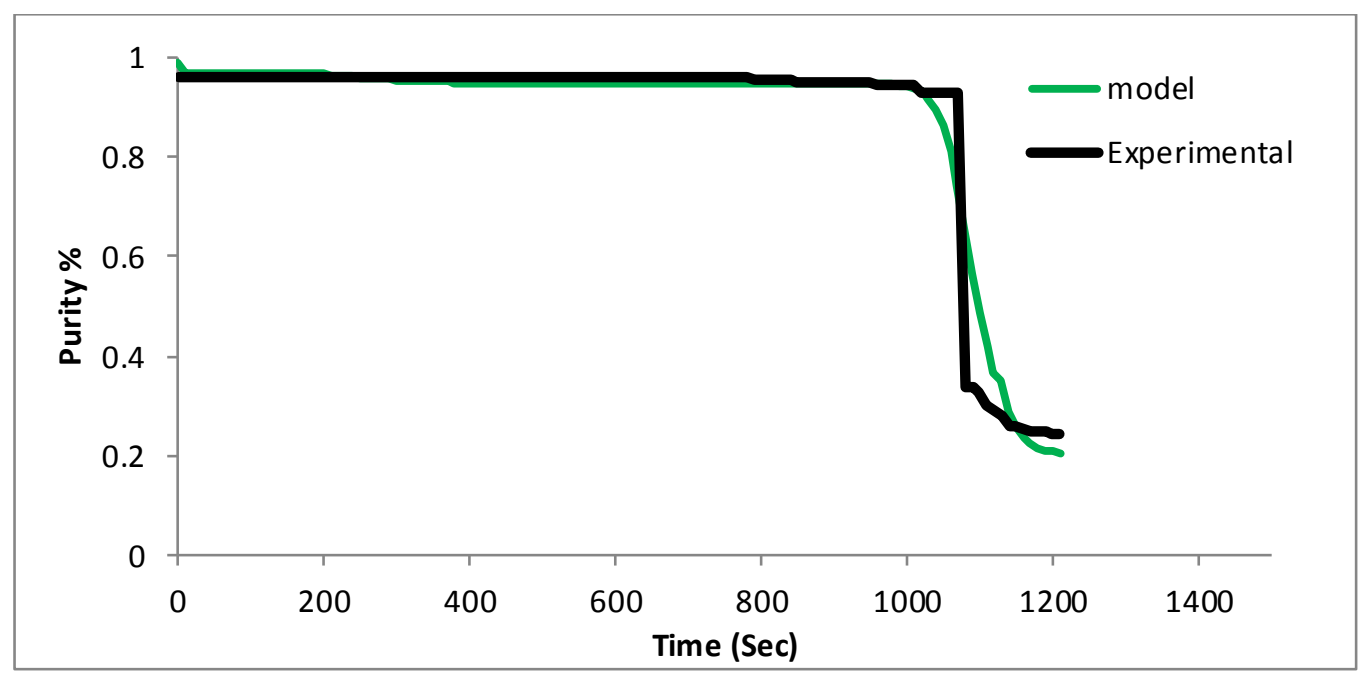

Fig. 2: Validation of breakthrough curve of single column adsorber with intermediate product pressurizing at 5 bar using data from literature [25]

Figures 3 represent the effect of product pressurizing pressure on the single column performance at the pressure range of 1-5 bar. Net product amount of oxygen at purity of $95 \%$ for each run increased with increases of product pressurizing pressure due to the reduction in effect of axial dispersion, and increasing adsorbent capacity. Thereby increase the breakthrough time and amount of oxygen production.

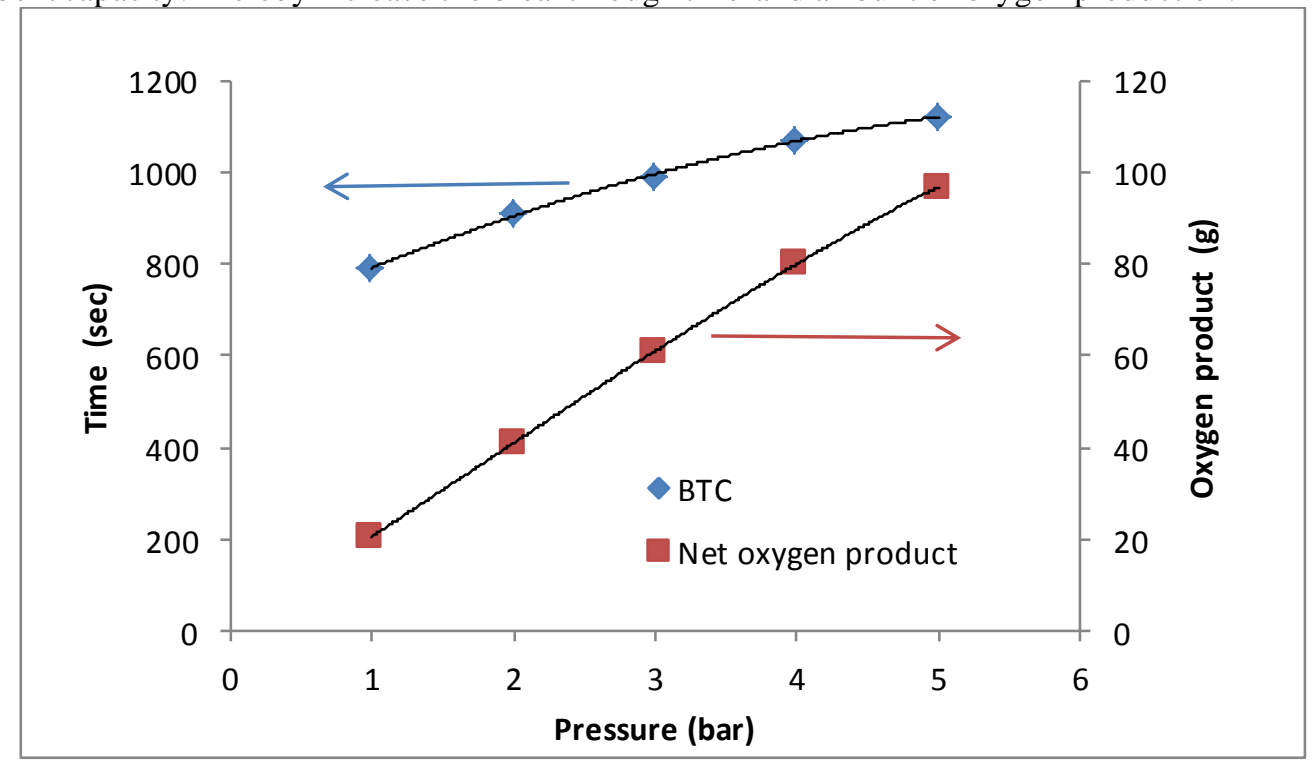

Fig. 3: Represents the effect of product pressurizing pressure on the amount of oxygen production and break through time of a single column adsorber.

\subsection{Two columns PSA process}

\subsubsection{Effect of adsorption time}

Figure 5 represents the effect of adsorption time in the range of 30-300s, an adsorption pressure of 5 bars, purge flowrate of 3 liter/min, and a product flowrate of 1 liter/min on the process product purity of four configurations processes. The results showed that the product purity of both the mode 2 and the mode 3 
decreased dramatically with increases of adsorption time from 50 s to $150 \mathrm{~s}$, while the product purity of both the mode 1 and mode 4 decreased slightly and kept over $90 \%$ with increases in adsorption time from 100 s to 250s. The width of the MTZ has a detrimental effect toward contamination of the product purity. Returning to the behavior of single column adsorber, where the MTZ width is clearly interpreted, in which a state of product pressurization. The steeper MTZ created and a long time required to reach the product end of column to contaminate the product purity in spite of a high amount of nitrogen entering the feed with increases of adsorption time. In turn, air pressurizing process caused contamination of the product early with increases of adsorption time. For the PSA process with pressure equalization step the effect of a wide MTZ reduced as a result of the equalization step.

To sum up, the purity is high at low adsorption times rather than long adsorption times. As well as the equalization step, product pressurization improved the process performance. However, the unique performance is dominated with product pressurization plus equalization step. The results are in agreement with Jee et al.[11,12], and in disagreement with Mofarahi et al.[17,18].

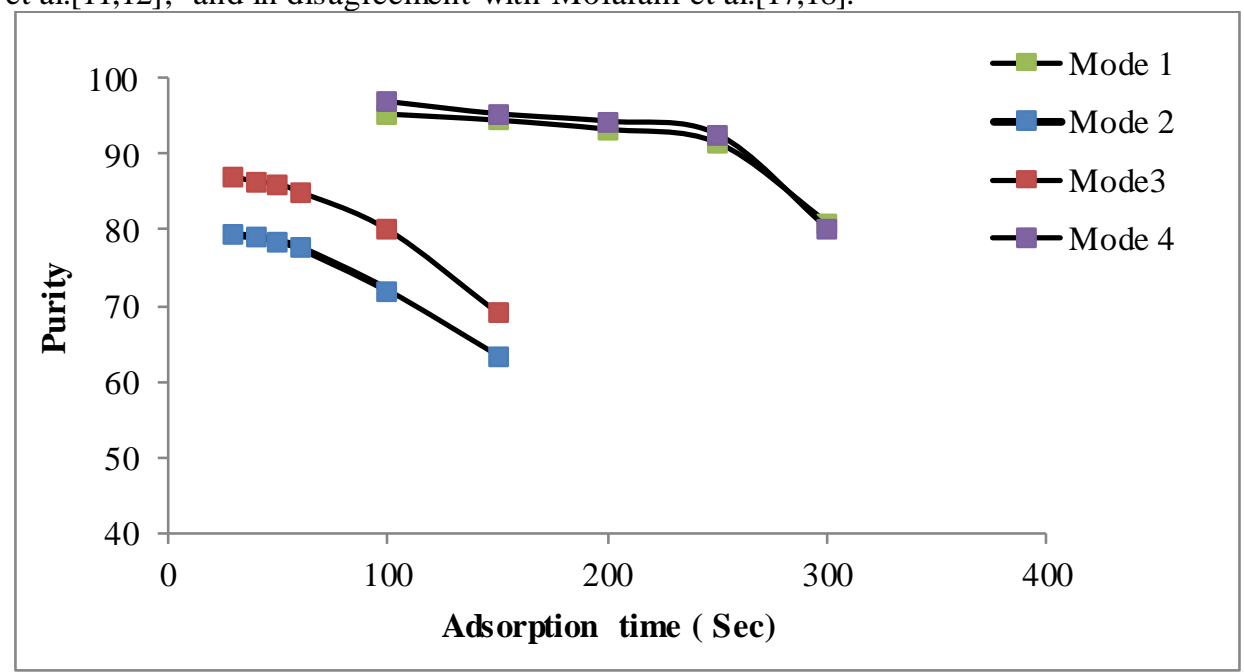

Fig. 4: Represents the effect of adsorption time on the PSA performance for four modes.

\subsection{Effect of purge flowrate}

Figure 6 represents effect of purge flowrate on the PSA performance through four configurations of PSA processes in the range of 1-15 liter/ $\mathrm{min}$, adsorption pressure of $5 \mathrm{bar}$, a product flowrate $1 \mathrm{liter} / \mathrm{min}$, and an adsorption time of $50 \mathrm{~s}$. The purity of oxygen in the effluent product of mode 1 process was kept constant at over $90 \%$ with increases of purge flowrate from 1 to 15 liter/min, and slight decreases observed with increases of the purge flowrate over $12 \mathrm{liter} / \mathrm{min}$. The same trend was observed with mode4. For the mode 3 the purity was kept over $80 \%$, and the purity decreased gradually with increases of purge flowrate over 4 liter/min as well as the same trend observed with mode 2 where the purity of oxygen decreased slightly with increase of purge flowrate over $3 \mathrm{liter} / \mathrm{min}$, and purity kept over 70\%. In general, the results showed that high purity observed at low purge flowrate than high flowrate. Gradually decreases in the purity with increases of purge flowrate due to increase amount of feed entrance to the process, therefore increase amount of nit rogen per one cycle which was led to decrease the purity at the product end. The results are in agreement with both of Jee et al.[11,12] and Abdel-Rahman et al.[26] and in disagreement with both of Mofarahi et al.[17,18] and Chou C. et al.[19]. 


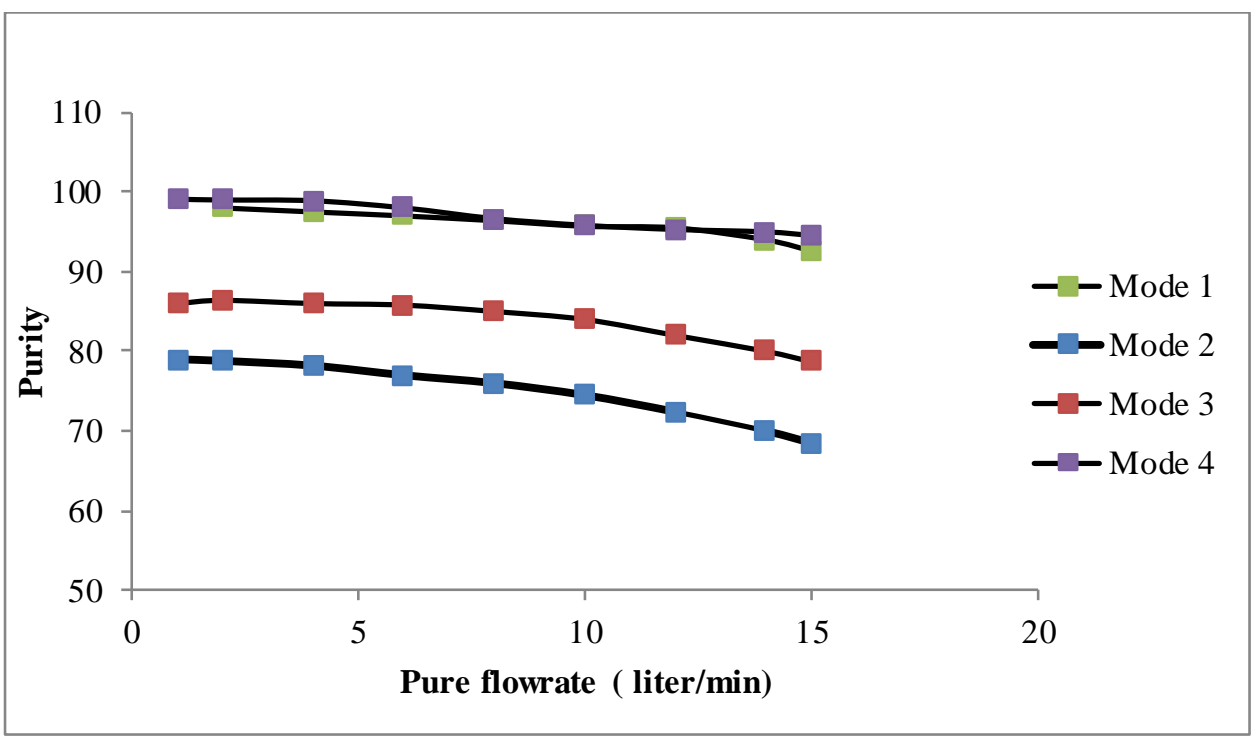

Fig. 5: Represents the effect of purge flowrate on the performance of four modes of PSA processes.

\subsection{Effect of product flowrate}

Figure 7 shows the effect of product flowrate on the products oxygen purity at a pressure of 5 bar, adsorption time of 50s, and a product flowrate of $1 \mathrm{liter} / \mathrm{min}$. The purity decreased with increases of product flowrate at all four configurations of the processes. This may be attributed to increases of feed flowrate with increases of product flowrate, causing early breakthrough curve and contamination of the product with heavy adsorbed material. The results are in agreement with Beeyani et a1.[15] and AbdelRahman et al.[26].

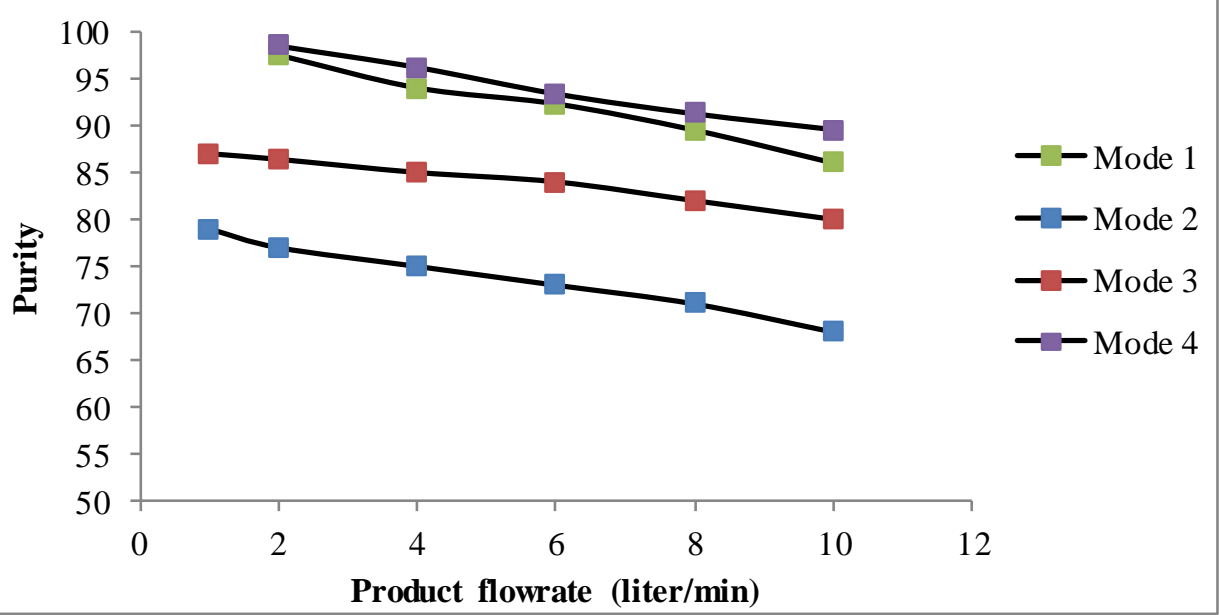

Fig. 6: Represents the effect of product flowrate on the performance offour modes of PSA processes.

\subsection{Energy consumption}

Figures 7 represent a relation between power consumption and process modes at a pressure of 5 bar, product flowrate of 1 liter/min, purge flowrate of $3 \mathrm{liter} / \mathrm{min}$, and adsorption of 50s. Figure 7 showed that the high power consumption observed by mode 2 because large amounts of feed flowed through the compressor to the process as well as the capacity of adsorbent being higher to adsorb more nitrogen from the feed. Low consumption is obtained by mode 3 and mode 4 due to a pressure equalization step, which contributed to min imize the energy consumption, because half of total adsorption preesure of produced bed 
is used to to pressure second bed. The power consumption by mode 1 is twice the power consumption to mode 3, approximately. The efficient and economic process is an indication of product purity and power consumption is mode 4 where the product purity is over $90 \%$ and power consumption is very low than other modes. The results in agreement with Santos et al.[20], Banerjee et al. [21], and Warmuzinski [22].

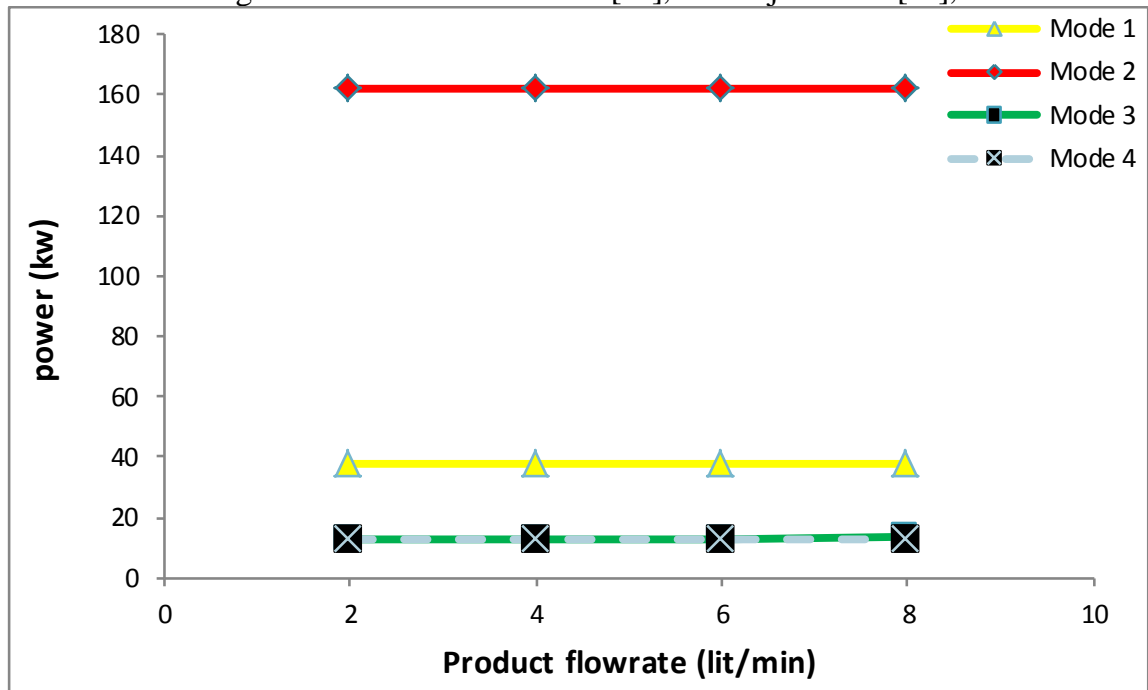

Fig. 7: Shows the relation between the power consumption and product flowrate of three modes of PSA processes.

\subsection{Recovery}

Figure 10 shows the effect of productivity on the product oxygen purity and recovery at a pressure of 5 bar, adsorption time of 50s, and product flowrate in the range of 1-10 liter/min. The purity decreased and the recovery increased with increases of productivity at all four configurations of the processes. This may be attributed to increases of feed flowrate with increases of productivity, thereby causing an early breakthrough curve and allowing for the contamination of the product. The results are in agreement with Beeyani et al.[15] and Abdel-Rahman et al.[26].

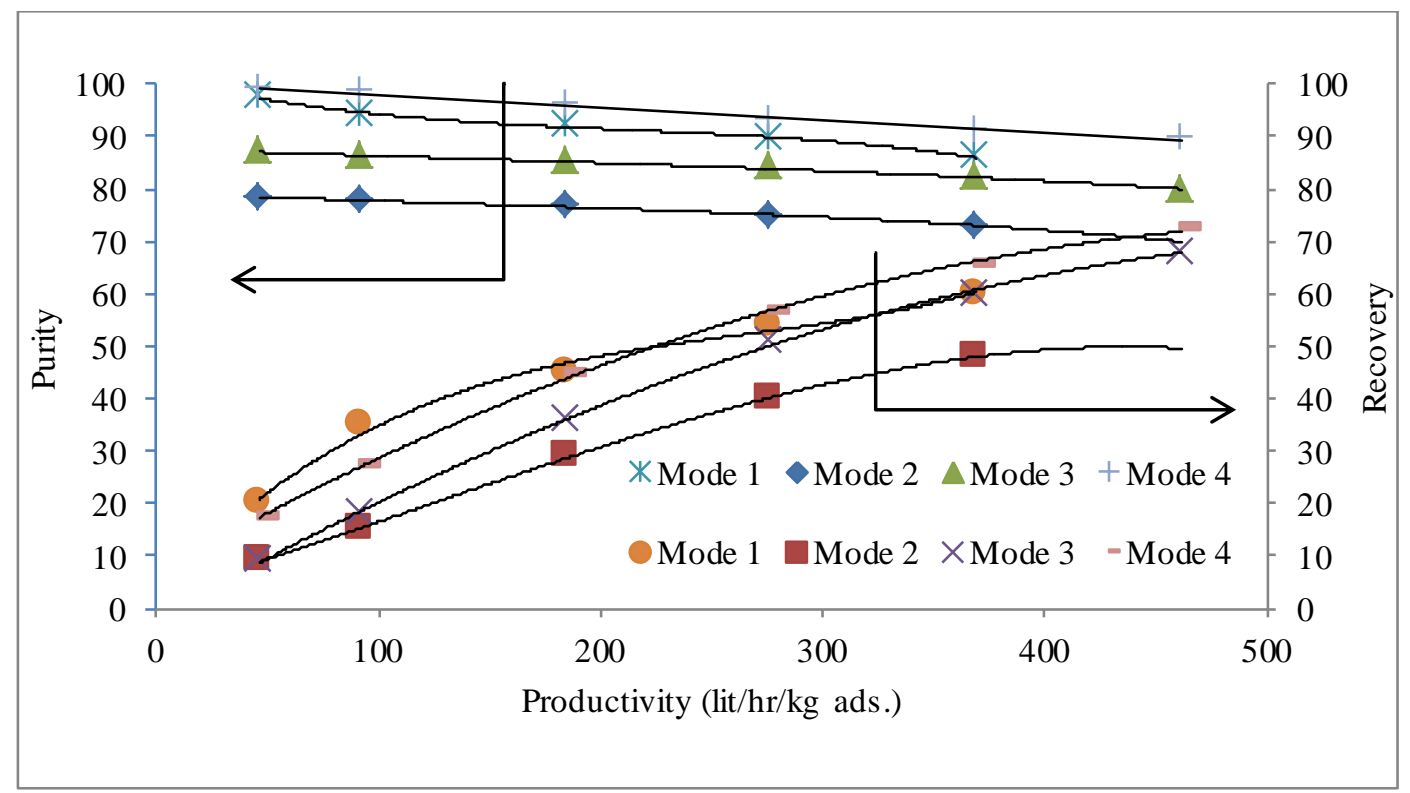

Figure 8: Effect of productivity on the performance of four modes of PSA processes. 


\section{Conclusions}

A verified mathematical model of single bed adsorber was used to investigate the effect of operating conditions on the processes performance of four configurations of PSA units. The results showed high performance of product pressurizing where the breakthrough time of 1000s and the MTZ is steeper, while the performance of separation was lower than air pressurizing at breakthrough time of 60s and wide MTZ. In addition, the net amount of oxygen with purity over $90 \%$ in the effluent line and breakthrough time are increased with increases of product pressurizing pressure.

The purity of Oxygen produced by mode 1 and mode 4 were slightly decreased from $95-90 \%$ with increasing in adsorption time from 100 s to 250 s. However, the purity decreased dramatically with increasing the adsorption time $>250$ s. Additionally, the purity of Oxygen produced from all designs decreased with increasing the purge flowrate and product flowrate .

Furthermore, lower power consumption was observed with mode 4, and mode 3 resulting in conserving in power consumption by approximately $75 \%$ compared with design 2 .

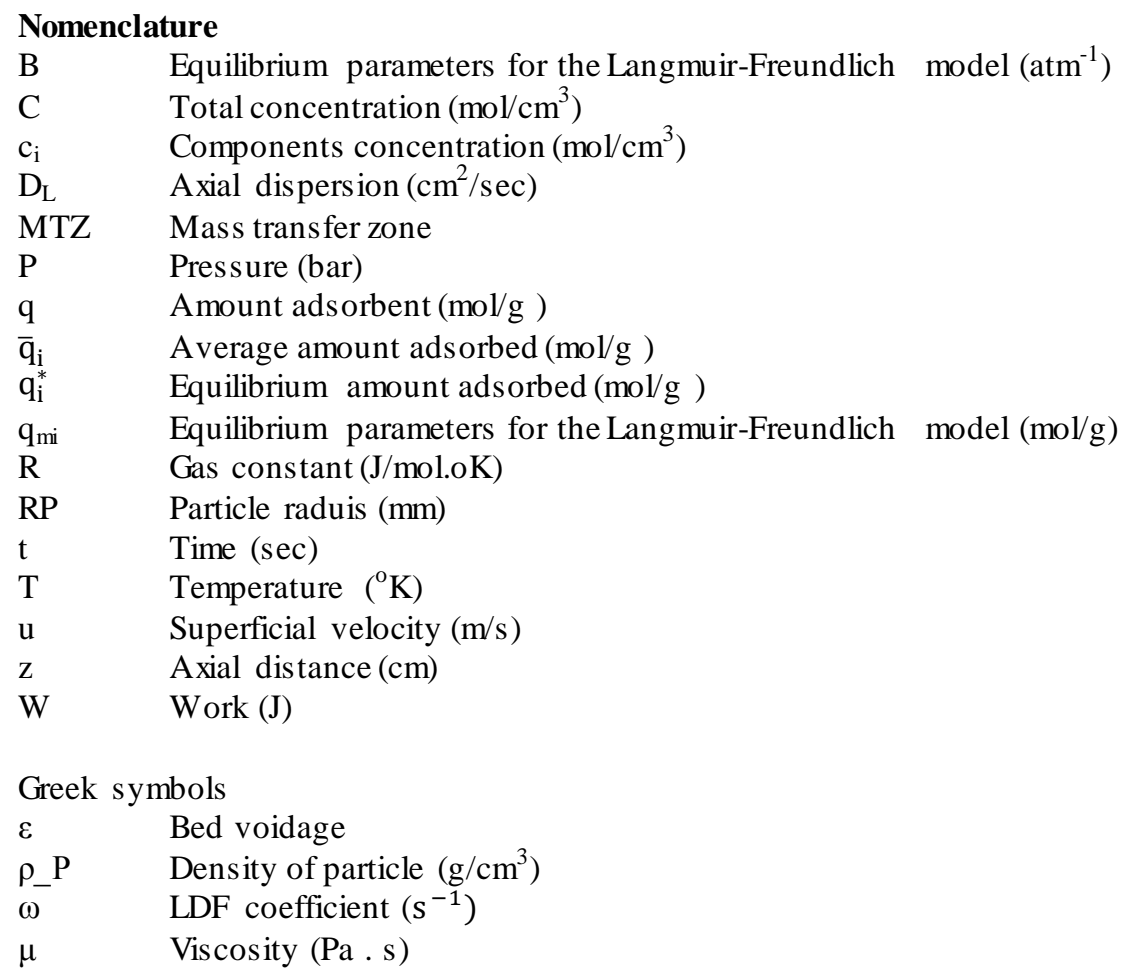

\section{References}

[1] Mhdi, A. H.: Capture of CO2 from power plants Using Different Adsorbent materials. KUJSS, volume 11, 2016.

[2] Liu, Y.; Sun, F.: Parameter estimation of a pressure swing adsorption model for air separation using multi-objective optimisation and support vector regression model. Expert Systems with Applications 2013, 40, 4496-4502.

[3] J., S. E.: A robust and user friendly software (tb-psa-ss) for numerical simulation of two-bed pressure swing adsorption ,Processes. Petroleum \& Coal 2015, 57, 13-18.

[4] Prajapati, S.; Patel, N.: A Novel Technique to Solve Mathematical Model of Pressure Swing Adsorption System for Oxygen Separation from Air, 2013.

[5] Rao, V. R.; Farooq, S.; Krantz, W.: Design of a two-step pulsed pressure-swing adsorption-based oxygen concentrator. AIChE journal 2010, 56, 354-370. 
[6] Nilchan, S.; Pantelides, C.: On the optimisation of periodic adsorption processes. Adsorption 1998, 4, 113-147.

[7] Santos, J.; Cruz, P.; Regala, T.; Magalhaes, F.; Mendes, A.: High-purity oxygen production by pressure swing adsorption. Industrial \& engineering chemistry research 2007, 46, 591-599.

[8] Santos, J.; Portugal, A.; Magalhaes, F.; Mendes, A.: Simulation and optimization of small oxygen pressure swing adsorption units. Industrial \& engineering chemistry research 2004, 43, 8328-8338.

[9] Chiang, A. S.; Hwong, M. Y.; Lee, T. Y.; Cheng, T. W.: Oxygen enrichment by pressure swing adsorption. Industrial \& engineering chemistry research 1988, 27, 81-85.

[10] Budner, Z.; Dula, J.; Podstawa, W.; Gawdzik, A.: Study and modelling of the vacuum swing adsorption (VSA) process employed in the production of oxygen. Chemical Engineering Research and Design 1999, 77, 405-412.

[11] Jee, J.; Jung, J.; Lee, J.; Suh, S.; Lee, C.: Comparison of vacuum swing adsorption process for air separation using zeolite 10X and 13X. Revue Roumaine de Chimie 2006, 51, 1095.

[12] Jee, J.-G.; Lee, J.-S.; Lee, C.-H.: Air separation by a small-scale two-bed medical O2 pressure swing ads orption. Industrial \& engineering chemistry research 2001, 40, 3647-3658.

[13] Kim, Y. H.; Lee, D. G.; Moon, D. K.; Byeon, S.-H.; Ahn, H. W.; Lee, C. H.: Effect of bed void volume on pressure vacuum swing adsorption for air separation. Korean Journal of Chemical Engineering 2014, 31, 132-141.

[14] Rege, S. U.; Yang, R. T.: Limits for air separation by adsorption with LiX zeolite. Indu strial \& engineering chemistry research 1997, 36, 5358-5365.

[15] Beeyani, A.; Singh, K.; Vyas, R.; Kumar, S.; Kumar, S.: Parametric studies and simulation of PSA process for oxygen production from air. Polish Journal of Chemical Technology 2010, 12, 18-28.

[15] Cruz, P.; Santos, J.; Magalhaes, F.; Mendes, A.: Cyclic adsorption separation processes: analysis strategy and optimization procedure. Chemical Engineering Science 2003, 58, 3143-3158.

[17] Mofarahi, M.; Shokroo, E. J.: Numerical Simulation of a Pressure Swing Adsorption for Air Separation. In 7th International Chemical Engineering Conference \& Exhibition, Kish, Iran, 2011.

[18] Mofarahi, M.; Towfighi, J.; Fathi, L.: Oxygen separation from air by four-bed pressure swing adsorption. Industrial \& Engineering Chemistry Research 2009, 48, 5439-5444.

[19] Chou, C.-t.; Huang, W.-C.: Simulation of a four-bed pressure swing adsorption process for oxygen enrichment. Industrial \& engineering chemistry research 1994, 33, 1250-1258.

[20] Santos, J.; Portugal, A.; Magalhaes, F.; Mendes, A.: Optimization of medical PSA units for oxygen production. Industrial \& engineering chemistry research 2006, 45, 1085-1096.

[21] Banerjee, R.; Narayankhedkar, K.; Sukhatme, S.: Exergy analysis of pressure swing adsorption processes for air separation. Chemical engineering science 1990, 45, 467-475.

[22] Warmnuzinski, k.: Effect of pressure equalization on power requirements in PSA systems. Chemical Engineering Science 2002, 57, 1475-1478.

[23] Li, Y.; Perera, S.; Crittenden, B. D.: Zeolite monoliths for air separation: Part 2: Oxygen enrichment, pressure drop and pressurization. Chemical Engineering Research and Design 1998, 76, 931-941.

[24] Serbezov, A.: Effect of the process parameters on the length of the mass transfer zone during product withdrawal in pressure swing adsorption cycles. Chemical engineering science 2001, 56, 4673-4684.

[25] Abdel-Rahman, Z. A.; Mhdi, A. H.; Ali, A. J.: Study the Behavior of Long Spiral Tube Adsorber for Oxygen Separation from Air. Eng. \&Tech. Journal 2013,31, 17.

[26] Abdulrahman Z. A. , M., A. H., Ali A. J.: Two Spiral Tubes Pressure Swing Adsorption Process For Oxygen Separation From Air. FNCES12 2012.

[27] Soo, C.; Lai, Y.; Chuah, T.; Mustapha, S.; Choong, T.: On the Effect of Axial Dispersion in the Numerical Simulation of Fast Cycling Adsorption Processes. Jurnal Tenologi 2005, 45, 1-13.

[28] Yang, J.; Lee, C. H.: Adsorption dynamics of a layered bed PSA for H2 recovery from coke oven gas. AIChE Journal 1998, 44, 1325-1334.

[29] Ko, D.; Siriwardane, R.; Biegler, L. T.: Optimization of pressure swing adsorption and fractionated vacuum pressure swing adsorption proces ses for $\mathrm{CO} 2$ capture. Industrial \& engineering chemistry research 2005, 44, 8084-8094. 